\title{
PENGARUH AKSESIBILITAS DAN DAYA TARIK TERHADAP LOYALITAS WISATA DENGAN AMENITAS SEBAGAI VARIABEL INTERVENING PADA DESTINASI WISATA TUK-TUK SIADONG KABUPATEN SAMOSIR
}

\author{
Pantas H. Silaban', Andri D. K. Silalahi ${ }^{2}$, Edgar Octoyuda ${ }^{3}$, Desi Sinaga ${ }^{4}$ \\ ${ }_{1,2,3,4}$ Program Pascasarjana Universitas HKBP Nommensen \\ e-mail: pantas.silaban@uhn.ac.id*1, andri.silalahi@student.uhn.ac.id², \\ edgar.tampubolon@student.uhn.ac.id ${ }^{3}$, desisinaga1997@gmail.com ${ }^{4}$
}

\begin{abstract}
This research aims to analyze the influence of accessibility and destination attraction on tourist loyalty mediated by the destination amenity. The research methodology uses the Structural Equation Modelling (SEM) to analyze the quantitative data were collected accidentally from the respondents in the destination. The sample method uses purposive random sampling with number of sample are 240 respondents. The respondents should meet the following criteria (1) who visit the destination at least 2 times or more, (2) who visit the destination at least in 2018. The results shows that (1) accessibility insignificantly influence the destination amenity, (2) destination attraction significantly influence the destination amenity, (3) accessibility insignificantly influence the tourists loyalty, (4) destination attractions insignificantly influence the tourists loyalty, (5) destination amenity insignificantly influence the tourists loyalty, (6) the destination amenity insignificantly mediated accessibility on tourists loyalty and (7) destination amenity insignificantly mediated the destination attraction on tourists loyalty.
\end{abstract}

Keyword : Akesiblitas, daya tarik wisata, amenitas, loyalitas wisatawan

\section{PENDAHULUAN}

Pariwisata merupakan salah satu sektor yang saat ini sedang mengalami perkembangan dan menjadi perhatian pemerintah. Destinasi wisata Danau Toba masuk dalam 10 bali baru yang ditetapkan menjadi sektor andalan dalam meningkatkan perekonomian.Sejalan dengan sasaran untuk meningkatkan perekonomian melalui pariwisata, pemerintah melakukan pembangunan insfraktruktur (jalan tol, jembatan) untuk menciptakan aksesibilitas yang mudah ke tempat wisata di Danau Toba.

Pembangunan pariwisata harus mencakup tiga hal yaitu, atraksi kelas dunia, akses transportasi serta amenitas yang memadai. Untuk itu kawasan Danau Toba mendapatkan anggaran Rp. 2,2 Triliun untuk pembangunan pariwisata. Kementerian Pariwisata (2015) menyatakan bahwa pariwisata berkontribusi terhadap devisa negara sebesar $12 \%$ dari total 12 komoditas yang menjadi sumber devisa

Pada kawasan Danau Toba terdapat beberapa destinasi wisata salah satunya adalah destinasi wisata Tuktuk Siadong Kabupaten Samosir. Hal yang unik dari Tuktuk Siadong adalah wisata budaya etnik yang masih terjaga dengan baik. didesa Tuktuk Siadong wisatawan asing yang datang berkunjung dapat menikmati berbagai macam kebudayaan asli tanah Batak seperti halnya kerajinan berupa ukiran kayu khas Batak, ulos (kain tradisional) batak, museum Batak, patung sigale-gale dan tari-tarian tradisional khas batak yang juga diiringi oleh alat musik batak yaitu gondang. Bukan hanya itu, rumahrumah yang ada di desa Tuktuk Siadong ini juga memiliki arsitektur yang masih kental dengan budaya batak.Hal tersebut menjadi daya tarik wisata bagi wisatawan.

Secara keseluruhan, anda bisa melakukan banyak hal di Tuktuk. Bisa aktivitas sederhanaa seperti bersepeda disekitar desa. Biasanya, dibutuhkan waktu hanya 2 jam. Waktu terbaiknya adalah dipagi atau disore hari lebih menghindari panasnya matahari disiang hari. Desa Tuktuk Siadong juga menewarkan berbagai jenis masakan termasuk masakan Batak dan Barat.

Menurut Utama (2017) Loyalitas merupakan konsistensi wisatawan untuk selalu mengunjungi sebuah destinasi meskipun pesaing menawarkan destinasi baru dengan atribut kualitas yang lebih superior. Artuger et al. (2013) menjelaskan faktor penentu loyalitas pada destinasi pariwisata ada dua.Pertama, intention to revisit the destination, maksudnya bahwa wisatawan menunjukkan loyalitasnya dengan mengunjungi kembali destinasi pariwisata terkait dimasa mendatang. Kedua, say positive things about the destination and recommendations to others, maksudnya bahwa wisatawan

Pengaruh Aksesibilitas dan Daya Tarik Terhadap Loyalitas Wisata dengan Amenitas Sebagai 


\title{
Volume 20 Nomor 2, September 2020
}

menunjukkan loyalitasnya dengan mengatakan hal-hal yang positif mengenai destinasi pariwisata kemudian merekomendasikan destinasi pariwisata tersebut ke orang lain.

Amenitas adalah segala bentuk fasilitas pendukung yang dapat digunakan oleh wisatawan untuk memenuhi kebutuhannya. Rossadi (2018). Di Tuktuk Siadong terdapat beberapa restoran dan hotel yang dapat menjadi fasilitas yang dapat dirasakan oleh wisatawan. Toba Village Inn, RedDoorz, OYO merupakan beberapa hotel yang tersedia disana. Adapun restaurant anatara lain yang ada di Tuktuk Siadong yaitu, Today's Café, Jenny's Restaurant, Maruba Restaurant dan sebagainnya.

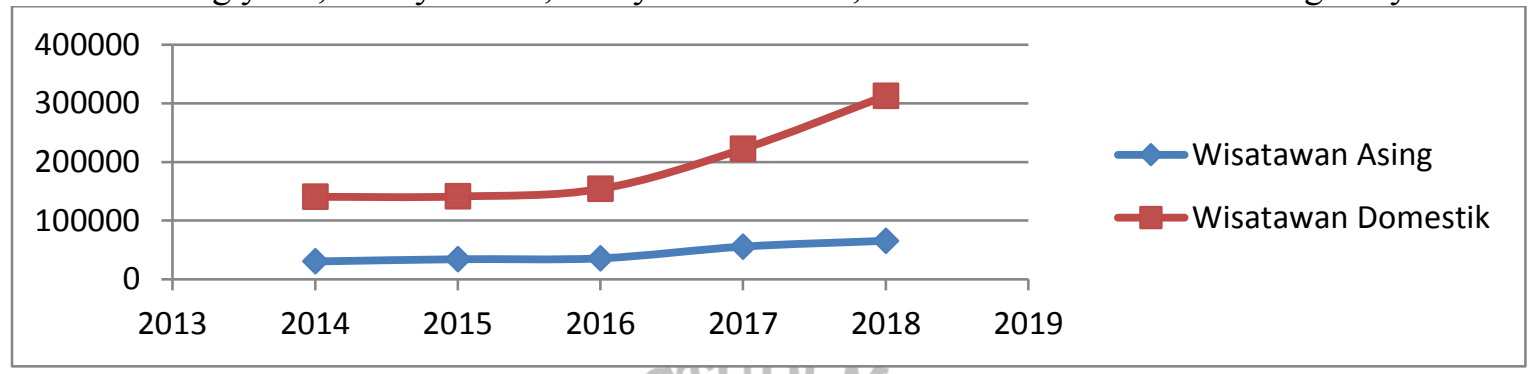

Gambar 1. Jumlah Kunjungan Wisatawan Kabupaten Samosir

Berdasarkan grafik diatas diketahui bahwa pada tahun 2014-2018 Kunjungan Wisatawan Asing sebanyak 30.450 orang, 34.248 orang, 35.825 orang, 55.771 orang, 65.724 orang serta kunjungan wisatawan domestic pada tahun yang sama sebanyak 140.634 orang, 141.215 orang, 154.905 orang,222.288 orang, 312.925 orang.Peningkatan jumlah wisatawan dari tahun ke tahun semakin bertambah dan menjadi pendorong bagi semua objek wisata yang ada diTuktuk Siadong Kabupaten Samosir.Hal ini berpengaruh positif dalam peningkatan pendapatan dan perkembangan kabupaten dan desa-desa yang ada dikabupaten Samosir dengan demikian objek wisata yang ada di kawasan kabupaten Samosir ini dapat memuaskan wisatawan yang berkunjung kewisata tersebut. Untuk dapat mengukur tingkat Loyalitas Wisata pada Destinasi Wisata Tuktuk Siadong yaitu melalui: Aksesibilitas dan Daya Tarik. Kedua faktor ini yang harus diperhatikan dalam menghitung sebarapa besar Loyalitas Wisata dan dapat menjadi masukan untuk keberlanjutan wisata tersebut.

\section{Loyalitas Wisatawan.}

\section{KAJIAN LITERATUR}

Menurut Utama, (2017) Loyalitas merupakān kónsistensi wisatawan untuk selalu mengunjungi sebuah destinasi meskipun pesaing menawarkan destinasi baru dengan atribut kualitas yang lebih superior. Loyalitas Wisatawan merupakan ketersediaan pelanggan untuk senantiasa memakai produk suatu perusahaan dalam jangka waktu yang panjang, bahkan menggunakannya secara ekslusif, merekomendasikan produk-produk tersebut pada orang lain.

Artuger et al. (2013) menjelaskan faktor penentu loyalitas pada destinasi pariwisata ada dua.Pertama, intention to revisit the destination, maksudnya bahwa wisatawan menunjukkan loyalitasnya dengan mengunjungi kembali destinasi pariwisata terkait dimasa mendatang. Kedua, say positive things about the destination and recommendations to others, maksudnya bahwa wisatawan menunjukkan loyalitasnya dengan mengatakan hal-hal yang positif mengenai destinasi pariwisata kemudian merekomendasikan destinasi pariwisata tersebut ke orang lain. Dari pendapat diatas dapat dikatakan bahwa Loyalitas Wisata adalah kesetiaan seseorang dimana Wisatawan yang mengunjungi sebuah Destinasi meskipun ada suatu Wisata yang baru.

\begin{abstract}
Aksesibilitas
Kabu (2019) mengatakan "accessibilities of the tourist destination, yaitu semua yang dapat memberi kemudahan kepada wisatawan untuk datang berkunjung pada suatu daerah tujuan wisata.Menurut definisi diatas bahwa aksesibilitas dipersepsikan sebagai sebuah sarana kemudahan wisatawan mencapai tujuan. Menurut Rossadi dan Widayati (2018) Aksesibilitas adalah suatu alat sarana prasarana yang dapat memberikan kemudahan bagi seseorang yang akan melakukan perjalanan. Menurut pendapat diatas dapat dijelaskan bahwa aksesibilitas merupakan sebuah fasilitas untuk ditemukan dan mudah dicapai oleh wisatawan.
\end{abstract}




\section{Volume 20 Nomor 2, September 2020}

Dalam pengembangan pariwisata sebagai sebuah sistem, faktor aksesibilitas, baik berupa perencanaan perjalanan, penyediaan informasi mengenai rute dan destinasi, ketersediaan sarana transportasi, akomodasi, ataupun kemudahan lain untuk mencapai destinasi menjadi penentu hasilnya peluang pengembangan destinasi. Aksesibilitas juga menyangkut infornasi kawasan pengembangan bagi calon wisatawan mengingat keunikan destinasi.

Aksesibilitas merupakan kemudahan untuk mencapai daerah tujuan wisata yang dimaksud melalui berbagai media transportasi, udara, laut, atau darat.Aksesibilitas sangat memengaruhi keputusan para calon wisatawan untuk datang ke suatu daerah tujuan wisata. (Muljadi, 2009). Berdasarkan menurut pendapat para ahli diatas maka dapat disimpulkan sebuah definisi mengenai aksesibilitas wisatawan sebagai sarana wisatawan untuk dapat lebih mudah mengakses lokasi wisatawan, dengan adanya aksesibilitas maka para wisatawan dapat lebih mudah dan cepat sampai pada lokasi wisatawan tersebut.

\section{Daya Tarik Wisata.}

Daya tarik wisata yang juga disebut objek wisata merupakan potensi yang menjadi pendorong kehadiran Wisatawan ke suatu daerah tujuan Wisata.Menurut Gunn (1998) dikutip dari Nasution (2018) bahwa Daya Tarik wisata dapat dipilih berdasarkan karakter khasnya.Daya Tarik Wisata yang terikat pada lokasi, tidak dapat dipindahkan dan dapat dinikmati hanya ditempat keberadaanya, dapat dilihat dan dinikmati tanpa dipersiapkan terlebih dahulu.

Menurut Rossadi dan Widayati (2018) Atraksi atau daya tarik wisata merupakan segala sesuatu yang memiliki keunikan, keindahan, dan nilai yang berupa keanekaragaman kekayaan alam, budaya, dan hasil buatan manusia yang menjadi sasaran atau tujuan kunjungan wisatawan (UU No.10 tahun 2009). Menurut Wardhani (2008) dalam Suharto (2019), Daya tarik adalah sebuah daerah yang mempunyai daya tarik wisata dapat dikatakan layak dikunjungi wisatawan bila ada kegiatan yang dapat dilakukan ditempat tersebut adalah:

a. Something to see (sesuatu yang dapat dilihat), seperti keindahan/kunikan alam, bangunan sejarah, kesenian/budaya stempat.

b. Something to do (sesuatu yang dapat dilakukan), seperti naik sampan, mencoba makanan tradisional, menari dengan penari local dan lain-lain.

c. Something to buy (sesuatu yang dapat dibeli), untuk memenuhi kebutuhan wisatawan untuk belanja,

Dari pendapat diatas dapat dikatakan bahwa daya tarik wisata adalah komponen utama Pariwisata, namun sering kali karakter daya tarik itu tidak cukup kuat untuk menahan wisatawan agar tinggal lebih lama dan menarik wisatawan agar datang kembali.Maka dari itu daya tarik wisata harus diperkuat dengan sungguhan pertunjukan atau diciptakan suatu peristiwa sehingga dapat memberikan kesan yang memikat wisatawan.

\section{Amenitas}

Menurut Rossadi dan Widayati (2018) Amenitas merupakan berbagai rangkaian fasilitas yang disediakan oleh suatu tempat tujuan Wisata yang digunakan untuk memenuhi kebutuhan pengunjung atau Wisatawan yang datang. Menurut Cahyani dan Aditya (2014) dalam Rossandi dan Widyawati (2018) amenitas yaitu berbagai Fasilitas seperti tempat-tempat penginapan, restoran, dan transportasi lokal yang mungkin wisatawan berpergian di tempat tersebut serta alat-alat komunikasi yang lainnya.

\section{METODE PENELITIAN}

Penelitian ini menggunakan metode penelitian metode kuantitatif. Metode kuantitatif adalah metode penelitian yang berlandaskan pada filsafat positivisme, digunakan untuk meneliti pada populasi atau sampel tertentu, teknik pengambilan sampel pada umumnya dilakukan secara random, pengumpulan data menggunakan instrumen penelitian, analisis data bersifat kuantitatif/statistik dengan tujuan untuk menguji hipotesis yang telah ditetapkan (Sugiyono, 2010). Jenis pendekatan yang digunakan dalam penelitian ini adalah penelitian explanatory research. Penelitian explanatory research yaitu penelitian yang menjelaskan, penelitian yang bertujuan untuk menganalisis hubungan-hubungan 


\section{Volume 20 Nomor 2, September 2020}

antara satu variabel dengan variabel lainnya atau bagaimana suatu variabel mempengaruhi variabel lainnya (Umar, 1999).

Sumber data primer merupakan sumber data yang dihimpun langsung dari responden dengan menggunakan instrumen daftar pertanyaan atau pernyataan (Kuesioner). Objek penelitian ini adalah wisatawan yang berkujung ke tempat wisata Tuktuk Siadong Kabupaten Samosir. Penelitian ini dilakukan pada periode tahun 2018 - 2019. Teknik pengambilan sampel yang digunakan dalam penelitian ini adalah Purposive Sampling dengan jumlah yang disarankan adalah 5 - 10 kali jumlah manifest seluruh variabel laten yang selanjutnya ditentukan berjumlah 240 sampel. Analisis data yang digunakan dalam penelitian ini yaitu dengan analisis statistik deskriptif yang bertujuan untuk menganalisa data dengan cara mendeskripsikan atau menggambarkan data yang telah terkumpul sebagaimana adanya tanpa bermaksud membuat kesimpulan yang berlaku untuk umum.

\section{HASIL PENELITIAN}

Objek penelitian ini adalah wisatawan yang berkujung ke tempat wisata Tuktuk Siadong Kabupaten Samosir. Langkah pertama dalam menyajikan data penelitian adalah dengan mendeskripsikan data karaktersitik responden penelitian. Berikut ini adalah karakteristik responden dalam penelitian ini:

Tabel 1. Karakteristik Responden Penelitian

\begin{tabular}{|c|c|c|}
\hline Karakteristik & Nilai & Persentasi $(\%)$ \\
\hline \multicolumn{3}{|l|}{ Jenis Kelamin } \\
\hline Laki - laki & 88 & 51,8 \\
\hline Perempuan & 82 & 48,2 \\
\hline \multicolumn{3}{|l|}{ Usia (Tahun) } \\
\hline $20-30$ & 114 & 67,1 \\
\hline $31-45$ & 29 & 17,1 \\
\hline$>45$ & 27 & 15,9 \\
\hline \multicolumn{3}{|l|}{ Pekerjaan } \\
\hline Mahasiswa & 101 & 59,4 \\
\hline Aparatur Sipil Negara & 15 & 8,8 \\
\hline Wiraswasta & 12 & 7,1 \\
\hline Lainnya $A$ IOLIK & 42 & 24,7 \\
\hline \multicolumn{3}{|l|}{ Pendapatan (juta) } \\
\hline $1-3$ & 131 & 77,1 \\
\hline $3-5$ & 15 & 8,8 \\
\hline$>5$ & 24 & 14,1 \\
\hline \multicolumn{3}{|l|}{ Frekuensi Kunjungan (kali) } \\
\hline $2-3$ & 132 & 77,6 \\
\hline $4-5$ & 23 & 13,5 \\
\hline $6-7$ & 3 & 1,8 \\
\hline$>7$ & 12 & 7,1 \\
\hline
\end{tabular}

Sumber: Data Primer Penelitian, 2020

Penelitian ini dilakukan pada periode tahun 2018 - 2019 dimana dalam penelitian ini ada sebayak 170 responden dari 240 sampel. Karakteristik mengenai responden dalam penelitian ini telah dijelaskan seperti pada table 2 di atas yang dikategorikan berdasarkan jenis kelamin, usia, pekerjaan, pendapatan dan frekuensi kunjungan pada destinasi wisata yang menjadi objek dalam penelitian ini. Selanjutnya adalah langkah langkah analisis data dalam penelitian ini menggunakan yang dimulai dengan pengujian validitas dan reliabilitas data. Pengujian validitas data dalam penelitian ini dapat dilaksanakan dengan menggunakan instrumen confirmatory factor analysis (CFA) dan reliabilitas dengan menggunakan average varians extracted (AVE). Berikut ini adalah hasil pengujian validitas dan reliabilitas dalam penelitian ini : 
Tabel 2. Hasil Pengujian CFA dan AVE

\begin{tabular}{|c|c|c|c|c|}
\hline Variabel & Konstruk Manifest & CFA & AVE & Kesimpulan \\
\hline \multirow[t]{3}{*}{ Aksesibilitas } & $\mathrm{AI}$ & 1,00 & \multirow[t]{3}{*}{0,85} & \multirow[t]{3}{*}{ Supported } \\
\hline & AKJ & 0,98 & & \\
\hline & ATAP & 0,78 & & \\
\hline \multirow[t]{7}{*}{ Daya Tarik } & BS & 0,83 & \multirow[t]{7}{*}{1,51} & \multirow[t]{7}{*}{ Supported } \\
\hline & PM & 1,56 & & \\
\hline & HSB & 1,04 & & \\
\hline & KT & 1,46 & & \\
\hline & $\mathrm{PA}$ & 0,98 & & \\
\hline & $\mathrm{PG}$ & 1,52 & & \\
\hline & IK & 1,00 & & \\
\hline \multirow[t]{7}{*}{ Amenitas } & $\mathrm{A}$ & 1,12 & \multirow[t]{7}{*}{1,08} & \multirow[t]{7}{*}{ Supported } \\
\hline & $\mathrm{RTT}$ & 0,61 & & \\
\hline & TU & 0,84 & & \\
\hline & $\mathrm{RA}$ & 0,98 & & \\
\hline & SS & 1,46 & & \\
\hline & $\mathrm{TP}$ & 1,08 & & \\
\hline & $\mathrm{TI}$ & 1,00 & & \\
\hline \multirow[t]{3}{*}{ Loyalitas Wiastawan } & MI & 0,71 & \multirow[t]{3}{*}{0,79} & \multirow[t]{3}{*}{ Supported } \\
\hline & SRT & 0,85 & & \\
\hline & SBTM & 1,07 & & \\
\hline
\end{tabular}

Sumber : Hasil Pengolahan Data Penelitian, 2020

Tabel di atas menunjukkan seluruh asumsi untuk pengujian validitas yaitu CFA > 0,60 dan AVE $>0,05$ adalah terpenuhi. Untuk itu dapat disimpulkan bahwa seluruh item dalam konstruk penelitian ini adalah valid dan reliabel. Lebih lanjut, data dalam penelitian ini adalah layak digunakan untuk tahap pengujian analisis data hingga pengujian model dan memperoleh hasil pengujian hipotesis.

Pengujian hipotesis dalam penelitian ini dilaksanakan dengan menggunakan dua metode yaitu metode langsung (direct effect) dan metode tidak langsung (indirect effect). Sebelum masuk dalam tahap pengujian hipotesis, Langkah pertama adalah melaksanakan pengujian model structural penelitian. Dalam pengujian model structural terdapat kriteria yang harus dipenuhi yang terdiri dari; chi square mendekati nol; RATIO < 2,00, RMSEA < 0,08; GFI > 0,90; CFI > 0,90; TLI > 0,90, p < 0,05 dan AGFI > 0,90. Berikut adalah hasil pengujian model structural ahir setelah dilakukan modifikasi model berdasarkan kriteria modification indices yang dibentuk dari output analisis SEM dengan menggunakan Amos versi 22 pada table dibawah ini:

Tabel 4. Evaluasi Goodness of Fit Model

\begin{tabular}{|c|c|c|c|}
\hline Goodness of Fit Index & Cut of Value & Value & Kesimpulan \\
\hline Chisquare & Mendekati 0 & 143,545 & Model Baik \\
\hline RATIO & $<2,00$ & 1,063 & Model Baik \\
\hline RMSEA & $<0,08$ & 0,019 & Model Baik \\
\hline GFI & $\geq 0,90$ & 0,928 & Model Baik \\
\hline CFI & $\geq 0,90$ & 0,982 & Model Baik \\
\hline NFI & $\geq 0,90$ & 0,784 & Marginal \\
\hline TLI & $\geq 0,90$ & 0,975 & Model Baik \\
\hline Probability & $\geq 0,05$ (Marginal) & 0,291 & Marginal \\
\hline AGFI & $\geq 0,90$ & 0,888 & Marginal \\
\hline
\end{tabular}

Sumber: Hasil Pengolahan Data Penelitian, 2020

Tabel di atas menunjukkan bahwa masih terdapat dari GOF index yang masih marginal, akan tetapi nilai tersebut tidak termasuk dalam nilia kritis atau nilai minimum seperti RMSEA, GEI, CEI 


\section{Volume 20 Nomor 2, September 2020}

yang sudah memenuhi kriteria maka seluruh GOF indeks dinyatakan model structural adalah sudah dapat digunakan sebagai model untuk menguji hipotesis dalam penelitian.

Selanjutnya adalah pengujian hipotesis. Berikut ini adalah hasil pengujian hipotesis dalam penelitian yang dijelaskan dalam table sebagai berikut ini:

Tabel 5. Rangkuman Pengujian Hipotesis Direct Effect

\begin{tabular}{|l|l|l|}
\hline Hubungan & Keterangan & Keputusan \\
\hline Amenitas--- > Aksesibilitas & Tidak Signifikan & $\mathrm{H}_{0}$ ditolak \\
\hline Amenitas --- > Daya Tarik & Signifikan & $\mathrm{H}_{0}$ diterima \\
\hline Loyalitas Wisata--- > Aksesibilitas & Tidak Signifikan & $\mathrm{H}_{0}$ ditolak \\
\hline Loyalitas Wisata --- > Daya Tarik & Tidak Signifikan & $\mathrm{H}_{0}$ ditolak \\
\hline Loyalitas Wisata --- > Amenitas & Tidak Signifikan & $\mathrm{H}_{0}$ ditolak \\
\hline
\end{tabular}

Sumber: Hasil Pengolahan Data Penelitian, 2020

Berdasarkan pada table 5 di atas di atas maka dapat dilihat bahwa (1) pengaruh yang tidak signifikan variable amenitas terhadap aksesibilitas, (2) terdapat pengaruh yang signifikan variable amenitas terhadap daya Tarik wisata, (3) terdapat pengaruh yang tidak signifikan aksesibilitas terhadap loyalitas wisatawa, (4) terdapat pengaruh yang tidak signifikan variable daya Tarik terhadap loyalitas wisatawan, dan (5) terdapat pengaruh yang tidak signifikan amenitas terhadap loyalitas wisatawa.

\section{Kesimpulan}

\section{KESIMPULAN DAN SARAN}

Berdasarkan hasil penelitian, maka kesimpulan yang dapat ditarik adalah: variable amenitas berpengaruh tidak signifikan terhadap aksesibilitas sedangkan variable amenitas berpengaruh signifikan terhadap daya Tarik wisata, variabel daya tarik dan asesibilitas berpengaruh tidak signifikan terhadap loyalitas wisatawan, dan amenitas berpengaruh tidak signifikan terhadap loyalitas wisatawa.

\section{Saran}

Berdasarkan kesimpulan yang didapat dari penelitian ini, saran yang kiranya bermanfaat bagi pihak pengelola Destinasi Wisata Tuk-Tuk Siadong Kabupaten Samosir agar memperbaiki aksesibilitas dan amenitas untuk meningkatkan kunjungan wisatawan ke Tuk-Tuk Siadong Kabupaten Samosir.

\section{DAFTAR PUSTAKA}

Utama, I Gusti Bagus Rai. 2017. Pemasaran Pariwisata. Yogyakarta: ANDI OFFSET.

Nasution, Laila Wahida Rahma. "Faktor-Faktor yang Mempengaruhi Kepuasan Wisatawan Kota Berastagi”.Skripsi, Medan: Universitas Sumatera Utara, Tahun 2018.

Sugiyono. Metode Penelitian Kuantitatif, Kualitatif, dan R\&D. Alfabeta: Bandung, 2014.

Stevianus. 2014. Pengaruh Atraksi Wisata, Fasilitas Pengaruh Atraksi Wisata, Fasilitas dan Kualitas Pelayanan terhadap Kepuasan Pengunjung di Taman Margasatwa Ragunan Jakarta. Jurnal Ekonomi dan Bisnis. 19 (3). Fakultas Ekonomi, Universitas Gunadarma.

Judisseno, Rimsky K. 2015. Aktivitas dan Kompleksitas Kepariwisataan. Jakarta: PT Gramedi Pustaka Utama.

Kotler, Philip. 2005. Manajemen Pemasaran, Edisi 12e..Jakarta: Penerbit Erlangga.

Lamidi dan Marjam D. R. 2013. Pengaruh Citra Objek Wisata Umbul Tlatar Boyolali terhadap Loyalitas Pengunjung dengan Kepuasan sebagaiVariabel Mediasi. Jurnal Ekonomi dan Kewirausahaan. 13 (1): 58-68. Fakultas Ekonomi, Universitas Slamet Riyadi Surakarta

Hermawan, H. 2017. Pengaruh Daya Tarik Wisata, Keselamatan, dan Sarana Wisata terhadap

Kepuasan serta Dampaknya terhadap Loyalitas Wisatawan. Jurnal Media Wisata. 15 (1).

Sekolah Tinggi Pariwisata ARS Internasional Bandung 